\title{
Association between angiogenesis soluble factors and disease progression markers in chronic hepatitis $\mathrm{C}$ patients
}

\author{
X. Salcedo Mora, P. Sanz-Cameno, J. Medina, S. Martín-Vílchez, L. García-Buey, M. J. Borque \\ and R. Moreno-Otero
}

Unit of Hepatology. Hospital Universitario de La Princesa. Universidad Autónoma. Madrid, Spain

\begin{abstract}
Objectives: our objectives were to compare angiogenesis soluble factor (ASF) levels in chronic hepatitis $\mathrm{C}(\mathrm{CHC})$ patients and healthy individuals, and to investigate potential associations between ASF levels and both histological and biochemical markers of disease progression.

Method: thirty-six patients (69\% males) positive for $\mathrm{HCV}$ RNA by PCR analysis were included in the study. All patients underwent liver biopsy before treatment. Serum levels of vascular endothelial growth factor (VEGF), soluble Flt-1 and Flk-1 receptors, placental growth factor (PIGF), angiopoietin-2 (Ang-2) and soluble Tie-2 receptor were determined by ELISA. Fifteen healthy subjects were used as controls.

Results: in comparison to healthy individuals, $\mathrm{CHC}$ patients showed significantly increased serum levels of proangiogenic factors PlGF ( $22 \pm 5$ vs. $18 \pm 8 \mathrm{pg} / \mathrm{ml}$; p $<0.05)$, Ang-2 (1265 \pm 385 vs. $833 \pm 346 \mathrm{pg} / \mathrm{ml} ; \mathrm{p}<0.005)$ and sFlt-1 $(95 \pm 22$ vs. 72 $\pm 14 \mathrm{pg} / \mathrm{ml} ; \mathrm{p}<0.0001)$. Interestingly, in $\mathrm{CHC}$ patients serum levels of VEGF and Tie-2 correlated with grade of inflammation, PIGF correlated with stage of fibrosis, and Flt- 1 and Flk-1 correlated with serum transaminase levels ( $p<0.05$ in all cases).

Conclusions: $\mathrm{CHC}$ patients showed increased serum levels of ASF, and a significant correlation was shown between serum levels of selected ASFs and grade of inflammation, stage of fibrosis, and transaminase levels.
\end{abstract}

Key words: Angiogenic. Soluble factors. Chronic hepatitis C. HCV-RNA. Fibrosis. Inflammation.

Salcedo Mora X, Sanz-Cameno P, Medina J, Martín-Vílchez S, García-Buey L, Borque MJ, Moreno-Otero R. Association between angiogenesis soluble factors and disease progression markers in chronic hepatitis $C$ patients. Rev Esp Enferm Dig 2005; 97: 699-706.

Recibido: 13-01-05.

Aceptado: 20-05-05.

Correspondencia: Ricardo Moreno-Otero. Unidad de Hepatología (planta 3). Hospital Universitario de La Princesa. Diego de León, 62. 28006 Madrid. Fax: 914022 299. e-mail: rmoreno.hlpr@salud.madrid.org

\section{INTRODUCTION}

Chronic hepatitis $\mathrm{C}$ (CHC) is a progressive disease characterized by the development of hepatocellular necrosis, inflammation, and fibrosis $(1,2)$. It has been shown that angiogenesis, the formation of new blood vessels, occurs in various liver diseases; hepatocellular carcinoma is the condition where this phenomenon has been best described, but it has also been recognized in $\mathrm{CHC}$ $(3,4)$. Immunohistochemical staining of $\mathrm{CHC}$ biopsies demonstrated the existence of characteristic capillary structures formed by CD31-positive endothelial cells (EC) in inflamed portal tracts (4). Another pathological condition featuring hepatic angiogenesis is experimental biliary cirrhosis, where vascular endothelial growth factor (VEGF) is produced in response to hepatocellular hypoxia, thereby inducing hepatic vascular proliferation (5).

Different cell types can produce VEGF in the liver, including hepatocytes, hepatic stellate cells, Kupffer cells and leukocytes from inflammatory infiltrates (6). There is evidence that hepatic stellate cells become activated in response to hypoxia, thereby increasing the expression of VEGF and its receptors (7). Multiple factors participate in the angiogenic response. Among them, the most thoroughly studied are those with mitogenic properties for EC, VEGF (8) being the best characterized. It belongs to a family made up by VEGF-A, VEGF-B, VEGF-C, VEGF-D and placental growth factor (PIGF). These factors bind to EC receptors with tyrosine kinase activity, such as Flt-1 and Flk-1. Angiopoietin-2 (Ang-2) is another molecule playing a central role in angiogenesis. In the initial phases of angiogenesis, it destabilizes vascular intercellular junctions, so that EC proliferation is facilitated. Its specific receptor is termed Tie-2 (9-11).

Induction of $\mathrm{EC}$ growth and differentiation requires that pro-angiogenic factors interact with their corresponding receptors as expressed and activated in the cells (9). 
This expression is normally localized to the cell surface, although a mechanism of proteolysis has been also described, which results in the appearance of receptors in the serum (12), these being then considered soluble factors. Determination of angiogenic factors and their soluble receptors in the serum might represent an important tool for the follow-up of diseases in which the occurrence of angiogenesis has been demonstrated at the molecular level, such as CHC, autoimmune liver diseases (6) and hepatocellular carcinoma (13). The latter pathology is a clear example where a significant relationship has been observed between serum VEGF levels and VEGF expression in tumor cells (14). This indicates that serum VEGF levels represent an indirect estimate of VEGF expression in the tumor (15).

Clinical follow-up of liver diseases often involves using invasive techniques to obtain biopsies, a procedure that is not free of risks. Therefore, it is important to identify serum markers that may provide information about the extent of disease progression without the need to biopsy the patient. The first step when trying to identify such factors is to focus on those molecules that play a pathophysiologically relevant role in the development of a given disease; then, its levels in the serum should be studied, and possible associations between those levels and disease progression should be investigated. Therefore, the objective of our study was to determine serum levels of ASFs in CHC patients, and to compare them with serum transaminase levels, with fibrosis stage, and with grade of inflammation in order to investigate whether or not they may provide relevant additional information about disease progression.

\section{METHODS}

Thirty-six consecutive patients $(69 \%$ males, $31 \%$ females) admitted to the Hepatology Unit at Hospital Universitario de La Princesa with chronic hepatitis $\mathrm{C}$ virus (HCV) infection (non-cirrhotics) were included in the study. Other requirements for inclusion were the absence of other liver diseases and the availability of a liver biopsy and frozen serum. Baseline data are shown in table I. A group of 15 patients negative for hepatitis B and C virus (73\% males, $27 \%$ females) with normal serum levels of liver enzymes was used for control. A baseline serum sample was taken from all healthy controls and patients before receiving any treatment.

$\mathrm{CHC}$ patients presented anti-HCV antibodies in their serum (16). Diagnosis of active HCV infection was done through HCV-RNA determination by PCR; viral load was evaluated by $\mathrm{HCV}$-Amplicor and HCV-Monitor (Roche Diagnostics, Basel, Switzerland), and genotyping was done through innoLiPA (Innogenetics, Zwijndreht, Belgium). AST (aspartate amino-transferase), ALT (alanine amino-transferase), GGT (gamma-glutamyl transpeptidase) and AP (alkaline phosphatase) levels,
Table I. Baseline demographic and laboratory data for patients

\begin{tabular}{|c|c|c|}
\hline & $\begin{array}{c}\text { Patients }(n=36) \\
\text { Mean } \pm S D\end{array}$ & $\begin{array}{c}\text { Healthy }(n=15) \\
\text { Mean } \pm S D\end{array}$ \\
\hline Age & $48 \pm 8$ & $39 \pm 12$ \\
\hline $\operatorname{Sex}(M: F)$ & $25: 11$ & $11: 4$ \\
\hline AST (U/L) & $46.3 \pm 41.7$ & $22.7 \pm 5.1$ \\
\hline $\operatorname{ALT}(\mathrm{U} / \mathrm{L})$ & $79.4 \pm 87.1$ & $22.9 \pm 9.5$ \\
\hline GGT (U/L) & $58.0 \pm 68.9$ & $23.9 \pm 21.6$ \\
\hline $\mathrm{AP}(\mathrm{U} / \mathrm{L})$ & $139.8 \pm 64.7$ & $54.0 \pm 20.3$ \\
\hline Viral load $\left(X 10^{5} \mathrm{IU} / \mathrm{mL}\right)$ & $7.3 \pm 7.2$ & - \\
\hline \multicolumn{3}{|l|}{ Genotype } \\
\hline 1 & 3 & - \\
\hline $1 a$ & 8 & - \\
\hline $1 b$ & 8 & - \\
\hline $2 a / 2 b$ & 3 & - \\
\hline $3 a$ & 11 & - \\
\hline 4 & 3 & - \\
\hline \multicolumn{3}{|l|}{ Histological assessment } \\
\hline \multirow[t]{3}{*}{ Grade } & 6 & - \\
\hline & 26 & - \\
\hline & 4 & - \\
\hline \multirow[t]{3}{*}{ Stage } & 10 & - \\
\hline & 20 & - \\
\hline & 6 & - \\
\hline
\end{tabular}

platelet counts, and HBV and HIV serology were determined in all patients.

Histological analysis: a liver biopsy was obtained from all patients and analyzed using the METAVIR classification system, which evaluates fibrosis stage in a scale from $\mathrm{F}_{0}$ to $\mathrm{F}_{4}$, where $\mathrm{F}_{0}$ represents absence of fibrosis; $\mathrm{F}_{1}$ : portal fibrosis with septa; $\mathrm{F}_{2}$ : few septa; $\mathrm{F}_{3}$ : abundant septa with cirrhosis; and $\mathrm{F}_{4}$ : established cirrhosis. Necroinflammatory activity was scored with a scale from $A_{0}$ to $A_{3}$, where $A_{0}$ represents absence of activity; $A_{1}$ : weak activity; $\mathrm{A}_{2}$ : moderate activity; $\mathrm{A}_{3}$ : severe activity. The histological evaluation was carried out by the Pathology Department at Hospital Universitario de La Princesa (A. García-Sánchez, MD).

ASF levels: serum samples were obtained from patients on the same day of liver biopsy and stored frozen at $-80^{\circ} \mathrm{C}$. Serum levels of VEGF, PIGF, Flt-1, Flk-1, Ang-2 and Tie-2 were quantified by ELISA (Quantikine $\mathrm{Hu}-$ man, R\&D SYSTEMS, UK).

Statistical analysis: the statistical analysis was performed using non-parametric tests, such as the MannWhitney test, Pearson's test, and a multiple linear correlation test.

\section{RESULTS}

Serum PlGF levels in patients were significantly higher than in controls (Table II). Statistically significant differences were also observed in Ang-2 and Flt-1 levels. However, no significant differences between patients and controls were found for VEGF, Tie-2 or Flk-1. 
Table II. Serum levels of angiogenesis soluble factors

\begin{tabular}{|c|c|c|c|c|c|}
\hline & \multicolumn{2}{|c|}{ Patients } & \multicolumn{2}{|c|}{ Healthy } & \multirow{2}{*}{$\begin{array}{c}\text { Statistical } \\
\text { significance }(p)\end{array}$} \\
\hline & Mean & Range & Mean & Range & \\
\hline $\mathrm{PIGF}(\mathrm{pg} / \mathrm{ml})$ & 20 & $15-38$ & 16 & $10-38$ & 0.01 \\
\hline Ang-2 (pg/ml) & 1172 & $846-2211$ & 723 & $470-1480$ & 0.005 \\
\hline Flt-1 (pg/ml) & 91 & $65-167$ & 69 & $52-101$ & 0.0001 \\
\hline Flk-1 (pg/ml) & 1944 & $949-3622$ & 2038 & $1046-3620$ & 0.1 \\
\hline VEGF (pg/ml) & 364 & $223-871$ & 312 & $242-258$ & 0.3 \\
\hline Tie-2 (ng/ml) & 1.9 & $1.1-2.6$ & 1.7 & $1.0-2.7$ & 0.3 \\
\hline
\end{tabular}

It must be highlighted that a significant correlation was found between fibrosis stage and PlGF levels in CHC patients $(\mathrm{p}=0.04)$ (Fig. 1). A correlation also existed between grade of inflammatory activity and VEGF levels $(p=0.04)$ and Tie-2 $(\mathrm{p}=0.05)$. As far as liver biochemistry is regarded, Flt-1 and Flk-1 were significantly correlated with AST $(\mathrm{p}=0,05$ and $\mathrm{p}=0.01)$ and ALT $(\mathrm{p}=0.01$ and $\mathrm{p}=0.01)$, respectively.

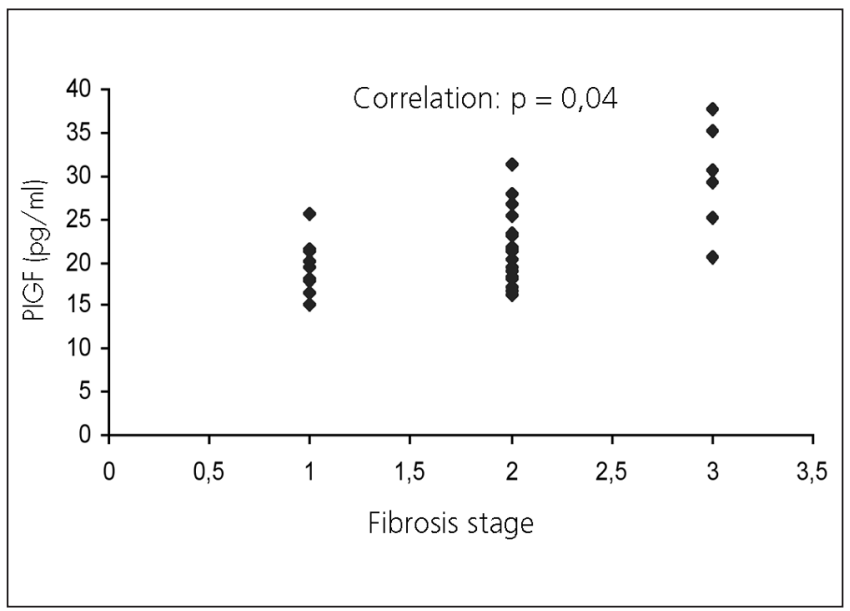

Fig. 1.

\section{DISCUSSION}

As previously mentioned, the occurrence of hepatic angiogenesis has been described in liver conditions such as viral hepatitis, cirrhosis, autoimmune hepatitis, primary biliary cirrhosis, and hepatocellular carcinoma $(3,4,17)$. Most studies carried out in this field report variations in the molecular expression of factors involved in angiogenesis $(14,15)$. As this phenomenon may play a pathogenic role in the development of liver damage, it may be hypothesized that the identification of surrogate markers in the serum that provide information about the extent of angiogenesis may represent a useful tool for disease characterization and follow-up. We currently know that new vascular structures associated with inflammatory infiltrates in periportal areas develop in $\mathrm{CHC}$ (4).
There are also data about some of the molecular mechanisms determining the formation of those neovessels (17). However, it is not known whether any pro-angiogenic factors may provide information about $\mathrm{CHC}$ progression, as already described in other pathologies. For instance, Oskun et al. observed higher serum VEGF levels in breast cancer patients versus healthy women $(137.2 \pm 64.7 \mathrm{pg} / \mathrm{ml}$ vs. $107.3 \pm 50 \mathrm{pg} / \mathrm{ml})$ (18). Similarly, Harris et al. found that, before treatment with Razoxane, renal cancer patients presented significantly elevated levels of Tie- 2 when compared to healthy controls $(0.74 \mathrm{pg} / \mathrm{ml}$ vs. $0.56 \mathrm{pg} / \mathrm{ml})$, as well as of Flt-1 $(77 \pm 9$ $\mathrm{pg} / \mathrm{ml}$ vs. $65 \pm 8$ ); afterwards, they observed that Tie-2 serum levels decreased in patients with stable disease $(66.9 \mathrm{pg} / \mathrm{ml})$, while they were increased in patients with progressive disease $(83 \mathrm{pg} / \mathrm{ml})$. The authors suggested that this factor might be used as a post-treatment followup marker $(18,19)$.

There are also examples of malignant tumors such as colon cancer and multiple myeloma where, in addition to reported variations in ASF levels between patients and healthy subjects, a prognostic value of some markers has been described (20). For instance, in multiple myeloma patients under treatment with the antiangiogenic drug thalidomide, serum levels of Flt- 1 and Tie- 2 were found to correlate with a poor prognosis (20). Similarly, serum VEGF levels have been proposed as prognostic markers in disseminated sarcoidosis patients (21) and in patients with inflammatory bowel disease (22).

Serum VEGF levels have also been suggested to correlate with platelet count in hepatocellular carcinoma patients. It has been reported that, in the presence of tumors, circulating platelets may transport huge amounts of VEGF in their granules, which are not reflected in serum levels. Therefore, it has been suggested that quantification of VEGF per platelet count might be used as a prognostic marker, since significantly higher figures were observed in hepatocellular carcinoma patients than in cirrhotics and healthy controls (23).

In the present study, levels of VEGF soluble receptors Flt-1 and Flk-1 were found to positively correlate to transaminase serum levels. Likewise, a significant correlation existed between PIGF levels and fibrosis stage; and VEGF and sTie-2 levels were correlated with inflammatory activity. The fact that associations were only found 
between ASF and fibrosis in some cases -inflammation and transaminases in other cases- might be related to the limited number of patients included in the study. In any case, angiogenesis is a multifactorial, extremely complex process involving a huge number of molecules and cells regulated at different levels by various factors. Therefore, it is conceivable that each ASF determined in the present study is stimulated and/or regulated by a different process, be it inflammation, fibrosis-associated hypoxia or nonspecific cell damage. Hence, it is not surprising that different degrees of association may be observed between each factor and grade of inflammation, fibrosis stage, or transaminase levels.

Our results may have important clinical implications. First, the demonstration of an association between variations in serum levels of ASF and CHC progression conceptually supports the critical role played by angiogenesis in chronic liver disease, as previously suggested $(6,24)$. Second, the determination of ASFs in parallel to viral load and fibrosis markers may provide complementary information for the evaluation of disease progression. This would be particularly useful in case a modulation of serum ASF levels in response to antiviral treatment was demonstrated, as this might help evaluate response to treatment and define the optimal follow-up strategy for each patient. Indeed, this will require the conduction of further prospective studies with larger patient cohorts.

It may be concluded that an increase in serum ASF levels exists in $\mathrm{CHC}$, possibly reflecting angiogenic activity in the liver; similarly, there seems to be a certain relationship between ASFs and histological damage. However, further studies are required in the future, with larger cohorts of patients, in order to confirm the pro-angiogenic factor, or combination of factors, potentially useful as markers of prognosis and progression in $\mathrm{CHC}$.

\section{ACKNOWLEDGEMENTS}

Dr. X. Salcedo wishes to acknowledge the BBVA Foundation-Carolina Foundation for their contribution to a grant, without which this study would have been impossible to carry out. This work has also been supported by funds from Instituto de Salud Carlos III (CO3/02) and Ministerio de Salud y Tecnología (SAF 2004-07885).

\section{REFERENCES}

1. Jiménez Sáenz M. Chronic viral hepatitis C. Rev Esp Enferm Dig 2004; 96: 146-7.

2. Aguilera V, Berenguer M. Hepatitis $C$ and fibrosis. Rev Esp Enferm Dig 2004; 96: 402-8; 409-14.

3. Ker CG, Chen HY, Juan CC, Lo HW, et. al. Role of angiogenesis in hepatitis and hepatocellular carcinoma. Hepato-gastroenterology 1999; 46: 646-50.

4. García-Monzón C, Sánchez-Madrid F, García-Buey L, García-Arroyo
A, et al. Vascular adhesion molecule expression in viral chronic hepatitis: evidence of neoangiogenesis in portal tract Gastroenterology 1995; 08: 231-41

5. Rosmorduc O, Wendun D, Coperchot C, et al. Hepatocellular hypoxia-induced vascular endothelial growth factor expression and angiogenesis in experimental biliar cirrhosis. Am J Pathol 1999; 155: 106573 .

6. Medina J, Arroyo AG, Sánchez-Madrid F, Moreno-Otero R. Angiogenesis in chronic inflammatory liver disease. Hepatology 2004; 39: 1185-95.

7. Ankoma-Sey V, Wang Y, Dai Z. Hypoxic stimulation of vascular endothelial growth factor expression in activated rat hepatic stellate cells. Hepatology 2000; 31: 141-8.

8. Yoshiji H, Kuriyama S, Yoshii J, Ikenaka Y, et al. Vascular endothelial growth factor and receptor interaction is a prerequisite for murine hepatic fibrogenesis. Gut 2003; 52: 1347-54.

9. Binetruy-Tournaire R, Demangel C, Malavaud B, et al. Identification of a peptide blocking vascular endothelial growth factor (VEGF)-mediated angiogenesis. EMBO J. 2000; 19: 1525-33.

10. Fujiyama S, Matsubara H, Nozawa Y, Maruyama K, et al. Angiotensin AT(1) and AT(2) receptors differentially regulate angiopoietin-2 and vascular endothelial growth factor expression and angiogenesis by modulating heparin binding-epidermal growth Factor (EGF)-mediated EGF receptor transactivation. Circ Res 2001; 88: 22 9

11. Achen MG, Jeltsch M, Kukk E, et al. Vascular endothelial growth factor D (VEGF-D) is a ligand for the tyrosine kinases VEGF receptor 2 (flk1) and VEGF receptor 3 (flt4). Proc Natl Acad Sci USA 1998; 95: 548-53.

12. Harris A, Reusch P, Baerlon B, Cheng H, et. al. Soluble Tie2 and Flt1 extracelular domains in serum of patients with renal cancer and response to antiangiogenic therapy. Clin Cancer Res 2001; 7: 1992-7.

13. Tanaka S, Sugimachi K, Yamashita Yi Y, Ohga T, Shirabe K, et al. Tie2 vascular endothelial receptor expression and function in hepatocellular carcinoma. Hepatology 2002; 35: 861-7.

14. Tanaka S, Mori M, Sakamoto Y, Makuuchi M, et al. Biologic significance of angiopoietin-2 expression in human hepatocellular carcinoma. J Clin Invest 1999; 103: 341-5.

15. Poon RT, Lau CP, Cheung ST, Yu WC, Fan ST. Quantitative correlation of serum levels and tumour expression of vascular endothelial growth factor in patients with hepatocellular carcinoma. Cancer Res 2003; 63: 3121-6.

16. Buti M, Cortina M, Chan H, Jardi R, Rodríguez F, Costa X, et al. Rapid method for the detection of anti-HCV antibodies in patients with chronic hepatitis C. Rev Esp Enferm Dig 2000; 92: $140-6$.

17. Medina J, Caveda L, Sanz-Cameno P, Arroyo AG, Martín-Vílchez S, et al. Hepatocyte growth factor activates endothelial proangiogenic mechanisms relevant in chronic hepatitis $\mathrm{C}$-associated neoangiogenesis. J Hepatol 2003; 38: 660-7

18. Coskun U, Gunel N, Sancak B, Gunel U, et al. Significance of serum vascular endothelial growth factor, insulin-like growth factor-I level and nitric oxide activity in breast cancer patients. Breast 2003; 12 : 104-10

19. Drevs J. Soluble markers for the detection of hypoxia under antiangiogenic treatment. Anticancer Res 2003; 23: 1159-61.

20. Sezer O, Jakob C, Eucker J, Niemoller K, et al. Serum levels of the angiogenic cytokines basic fibroblast growth factor (bFGF), vascular endothelial growth factor (VEGF) and hepatocyte growth factor (HGF) in multiple myeloma. Eur J Haematol 2001; 66: 83-8.

21. Sekiya M, Ohwada A, Miura K, Takahashi S, Fucuchi Y. Serum vascular endothelial growth factor as a possible prognostic indicator in Sarcoidosis. Lung 2003; 181; 259-65.

22. Griga T, Tromm J, Spranger J, May B. Increased serum levels of vascular endothelial growth factor in patients with inflammatory bowel disease. Scand J Gastroenterol 1998; 33: 504-8.

23. Kim SJ, Choi IK, Park KH, Yoon SY, Oh SC, et. al. Serum vascular endothelial growth factor per platelet count in hepatocellular carcinoma: correlations with clinical parameters and survival. Jpn J Clin Oncol 2004; 34: 184-90.

24. Lai WK, Adams D. Angiogenesis and chronic inflammation; the potential for novel therapeutic approaches in chronic liver disease. J Hepatol 2005; 42: 7-11. 